\title{
LINHAS PARA TECER POETNOGRAFIAS DANÇADAS
}

\author{
Maria Fernanda C. Miranda (Unicamp)
}

Renata de Lima Silva (UFG)

Este artigo discute a possibilidade de processo de criação na linguagem da dança brasileira contemporânea a partir de um olhar sensivel e etnográfico para o contexto sociocultural das fiandeiras e tecelãs de Hidrolândia (GO) e do Vale do Urucuia (MG) para a investigação de poetnografias dançadas - fragmentos dramatúrgicos tecidos na relação entre arte e antropologia, processo esse pautado na ideia de que a vivência em contextos marcados pelas tradições populares pode imprimir traços dessa identificação cultural na criação e performance em dança contemporânea.

DANÇA; PROCESSO DE CRIAÇÃO; CULTURA POPULAR BRASILEIRA.

MIRANDA, Maria Fernanda C.; SILVA, Renata de Lima. Linhas para tecer poetnografias dançadas. Textos escolhidos de cultura e arte populares, Rio de Janeiro, v.12, n.1, p. 73-86, mai. 2015. 


\section{THREADS TO WEAVE DANCED POETNOGRAPHY}

Maria Fernanda C. Miranda (Unicamp)

Renata de Lima Silva (UFG)

This paper discuss the possibility of creation processes in contemporary Brazilian dance based on a sensitive and ethnographic look at the socio-cultural context of the spinners and weavers of Hidrolândia (GO) and Vale Urucuia (MG). It aims at investigating danced poetnography - dramaturgical fragments weaved in the relationship between art and anthropology, a process founded on the idea that experiences in contexts marked by folk traditions can imprint traces of this cultural identification in dance creation and performance.

DANCE; CREATION PROCESS; BRAZILIAN POPULAR CULTURE.

MIRANDA, Maria Fernanda C.; SILVA, Renata de Lima. Linhas para tecer poetnografias dançadas. Textos escolhidos de cultura e arte populares, Rio de Janeiro, v.12, n.1, p. 73-86, mai. 2015. 


\section{O LUGAR DE ONDE SE FALA}

Quem olha olha de algum lugar, e esse lugar, muitas vezes, determina o olhar (Ana Cristina Colla, 2010)

Ao som da sua roca, ou roda como elas costumam chamar, uma senhora fiandeira residente em Goiânia, curiosa para entender que dança era aquela que iríamos fazer, nos pergunta: "isso aqui que eu tô fazendo vai virá dança? Uai, que interessante... Como estou te ensinando os conhecimentos da fiação, depois quero que ocê me ensine essa dança (risos) quem sabe vou até trabaiá mió, né?" (dona Joice, 11/01/2015).

Perceber o universo das fiandeiras e tecelãs como potencialidade de construção dramatúrgica em dança passa pelo lugar de onde se percebe, pois é esse lugar que vai determinar muito fortemente o modo como se olha e no que se vai transformar aquilo que se olha depois de visto e assimilado pelo artista. Assim, estamos aqui nós falando a respeito de um lugar em que a dança contemporânea busca diálogo com o universo das culturas populares brasileiras para calcar suas criações. Nesse lugar, essa dança é denominada por Silva (2012) dança brasileira contemporânea, sendo a noção de cultura popular brasileira identificada pela autora, a partir de Carvalho (2000), como um conjunto de produção e manifestação que, inserido nos atuais contextos de produção e comunicação de massa, cultiva ainda, mesmo que só no campo simbólico, valores e características das culturas tradicionais. Procurando escapar do plano ideológico que delimita fronteiras políticas e da ideia de identidade como algo unificado e homogêneo, Silva (2012) situa a dança brasileira contemporânea como potente catalisador da pluralidade da cultura brasileira e da possibilidade de um diálogo híbrido com a arte na contemporaneidade.

Sendo assim, a dança brasileira contemporânea pode, por meio de diferentes metodologias, debruçar-se sobre diferentes objetos de investigação e criação. Dentre as diversas possibilidades de atuação nessa área, ressaltamos os trabalho das artistas pesquisadoras Inaicyra Falcão dos Santos (2002) e Graziela Rodrigues (1997), ambas professoras do Departamento de Artes Corporais da Unicamp, e cujas abordagens de pesquisa, que tivemos a oportunidade de vivenciar, alicerçam dois importantes aspectos de nosso trabalho: a importância de compreender e adentrar o universo da cultura popular a partir de sua própria ancestralidade e história pessoal, e a relevância da pesquisa de campo. Aspectos esses que auxiliam no reconhecimento das fiandeiras e tecelãs como possibilidade de construção de uma dramaturgia em dança brasileira contemporânea.

No método bailarino-pesquisador-intérprete, de Graziela Rodrigues, através do eixo inventário pessoal, o bailarino é conduzido à investigação das memó- 
rias afetivas de seu corpo, reavivando-as pelo resgate de sua história pessoal, o que lhe permite redescobrir suas origens e o meio sociocultural que o envolve. Segundo Rodrigues (1997) a porta de entrada ao inventário pessoal é o espaçotempo das sensações mais profundas que dizem respeito a momentos de desenvolvimento do próprio corpo, sendo por isso então também chamado de inventário do corpo.

Inaicyra Falcão, por sua vez, opera com noções de corpo e ancestralidade, sendo a ancestralidade pensada não apenas como passado definido por elo familiar, mas também em termos do passado histórico mítico e cultural; e a corporeidade em questão, vista como uma atualização (recriação) do passado por meio de memória coletiva que se apresenta como tradição (SILVA, 2012). Assim, em seu trabalho propõe, como um canal de conexão com a ancestralidade, a experiência de técnicas corporais - não mediada por instituições de ensino ou por tecnologias modernas - com o gestual de ações de trabalhos braçais, tais como lavar roupa no rio ou ceifar o mato.

Em relação à pesquisa de campo, a vivência corporal efetiva no território pesquisado, um "co-habitar com a fonte", como coloca Rodrigues (1997), é uma forma de promover o encontro dessa história pessoal e ancestralidade com o universo do outro, em suas dimensões simbólica, corporal e histórica. Aqui se diferencia de um processo etnográfico, ao dar grande importância às apreensões cinestésicas que ocorrem principalmente pelas e nas relações vividas em campo, apreendendo não apenas movimentos gestuais, mas também impressões, sensações e possibilidades de movimento. Isso porque será por meio da essência da experiência em campo captada pelo corpo que o processo cênico será desenvolvido. Por essa razão, dá-se grande importância à preparação do corpo que irá a campo, sendo "corpo" entendido aqui como o "lugar do encontro" (RODRIGUES, 1997), isto é, o lugar da memória, da apropriação e da integração de experiências em processos de criação em dança. Essa preparação visa tornar o corpo mais sensível e favorecer uma apreensão mais profunda dos elementos pesquisados.

Dessa trajetória vivida, imaginada e dançada, como nas etapas iniciais de um processo de "tecedura" - em que o algodão é plantado, colhido e transformado em fios pelas mãos hábeis da fiandeira, que nele reconhece esse potencial de fiação -, percebeu-se, pela ancestralidade, história pessoal e afinidade, o universo feminino da fiação e tecelagem, universo das linhas, e as "mulheres de linhas" com suas cantorias em rodas ou na solitude. Percebeu-se também que o algodão que se buscava fiar é aquele do cerrado, sistema biogeográfico da região em que o encontramos e paisagem que circunscreve a história pessoal de uma das auto- 
ras, chegando, assim, à delimitação do campo nas cidades de Hidrolândia (GO) e Vale do Urucuia (MG).

A linha a ser fiada a partir desse algodão encontrou, nas noções de corpo limiar e encruzilhada e de poetnografia dançada, sua "roda" e seu "tear", para tecer uma dança tal como se tece uma grande e delicada colcha. Encontramo-nos, atualmente, nessa etapa da "tecedura": vendo no algodão (tradição da fiação e tecelagem em Minas Gerais e Goiás), colhido no algodoeiro (cultura popular do cerrado), o potencial de se transformar fios em tramas de um trabalho cênico em dança, composto de poetnografias dançadas.

\section{POETNOGRAFIA DANÇADA, CORPO LIMIAR E ENCRUZILHADA}

Inspiradas nos estudos da performance, em que Richard Schechner e Victor Turner exploram teorias e práticas da etnopoética, e adaptando-os para o contexto da dança brasileira contemporânea, Silva e Lima (2014, p. 157) encontram refúgio na ideia de "poetnografia dançada", isto é, uma tecedura dramatúrgica em dança construída a partir do apreendido durante experiência em campo e confrontado com o inventário pessoal, "instaurando um espaço de reflexão e fruição entre antropologia e arte".

O processo de poetnografar pela dança elementos pesquisados nas culturas populares, desde a pesquisa de campo, preparação e criação cênica, tem como base epistemológica as noções de corpo limiar e encruzilhada que Silva (2010) discute em sua tese de doutoramento. A noção de corpo limiar diz respeito ao estado corporal pelo qual transitam as noções de passado e presente, de sagrado e de profano, do eu e do outro; e a encruzilhada aparece aí como metáfora para o lugar (tempo-espaço) em que passado e presente se sobrepõem e, ainda, no qual perpassam questões relacionadas ao sagrado. Nessa perspectiva, a ancestralidade seria então uma atualização do passado, por meio de uma memória coletiva que se apresenta como tradição, isto é, uma recriação e não um retorno ao passado.

Para definir corpo limiar, Silva (2010, p. 69) parte da noção de liminaridade discutida em Tuner (1974) como o estado subjetivo de estar no limite entre dois estados de existência durante os ritos de passagem, bem como da abordagem de Schechener (2002), que amplia a noção de ritual, abarcando também o que o autor tratou como rituais seculares. Assim, a autora chega à noção de corpo limiar como aquela corporeidade pela qual transitam as noções de passado e presente, de sagrado e de profano, do eu e do outro.

A partir de Martins (1997), Silva (2010) aborda a encruzilhada na perspectiva do sistema filosófico-religioso de origem iorubá, isto é, o lugar de cruzamen- 
to de ruas ou trilhas, em que se faz oferenda para Exu e suas falanges. Não se trata de um lugar concreto e sim de metáfora da noção de tempo-espaço, um lócus de intersecções, marcado pela ancestralidade africana.

E é pela via dessas encruzilhadas que também se tece a identidade afro-brasileira, num processo móvel, identidade esta que pode ser pensada como um tecido e uma textura, nos quais as falas e os gestos mnemônicos dos arquivos orais africanos, no processo dinâmico de interação com o outro, transformam-se e reatualizam-se continuamente, em novos diferenciados rituais de linguagem e de expressão, coreografando a singularidade e alteridades negras (MARTINS, 1997, p. 26).

Assim, para Silva $(2010,2012)$ o corpo limiar é o próprio corpo da encruzilhada, na qual a assimilação da memória coletiva incorpora a herança cultural negroafricana no Brasil.

Se em um primeiro momento a ideia de encruzilhada aparece em Silva (2010), voltada especificamente para o contexto da cultura afro-brasileira, olhando atentamente para manifestações de dança popular, no desdobrar da encruziIhada anuncia-se a possibilidade de essa noção mediar a vivência e compreensão de outros contextos culturais, não necessariamente categorizados por expressões afro-brasileiras.

Ora, se a encruzilhada é justamente o lugar em que passado e presente se sobrepõem e ainda no qual perpassam questões relacionadas à ancestralidade e a um tempo-espaço de festejos, podemos pensá-la para além de manifestações populares "dançadas" e que não estejam necessariamente no contexto afro-brasileiro. As fiandeiras e tecelãs são corpos de encruzilhada. A história da fiação e tecelagem no Brasil demonstra o apego a uma tradição herdada e que é atualizada sempre que uma fiandeira se senta diante de sua roda, aparecendo assim como instância possível da encruzilhada.

Esse desdobrar da encruzilhada é uma possibilidade de salto sobre a linha abissal em que um recurso epistemológico do sul é utilizado como lente para olhar e compreender o mundo, afirmando uma construção de conhecimento descolonizadora. O pensamento abissal, demarcado por linhas cartográficas abissais, é definido por Boaventura de Souza Santos (2007) como uma herança da era colonial que tradicionalmente define relações políticas e culturais da contemporaneidade. Consistindo em divisão da realidade em dois universos distintos, os "deste lado da linha" e os "do outro lado da linha", que não se relacionam, o pensamento abissal atua para além das denominações pelas quais o colonialismo é conhecido, tornando "invisíveis" os saberes provenientes do sul (o outro lado da 
linha). Essa invisibilidade, segundo o autor, acaba por fundamentar, por meio da apropriação/violência, a visibilidade dos "deste lado da linha".

Em um pensamento pós-abissal, Santos (2007) propõe a ecologia dos saberes como forma de ordenamento da apropriação/violência, situando, assim, nossa perspectiva epistemológica na experiência social do outro lado da linha como um aprender com essa linha a partir da própria epistemologia por ela utilizada. Essa perspectiva propõe uma visão de mundo no reconhecimento da pluralidade de formas de conhecimento existentes e as possibilidades de interações entre elas num diálogo horizontal entre conhecimentos, sem comprometer a autonomia de cada um.

Existem em todo o mundo não só diversas formas de conhecimento da matéria, da sociedade, da vida e do espírito, mas também muitos e diversos conceitos e critérios sobre o que conta como conhecimento (SANTOS, 2007, p. 86).

Vivenciar afetos da roda de fiação e tecelagem como manifestações de encruzilhada, isto é, enxergando ali uma potência simbólica advinda de saberes populares para a criação de poetnografias dançadas, é, a nosso ver, uma forma de fazer e refletir a arte da dança de forma pós-abissal, reconhecendo no corpo seu potencial discursivo.

Considerando que o corpo em cena não é exatamente um corpo limiar e nem a cena é uma encruzilhada, como já apontado por Silva (2010, 2012), reivindicamos para a arte essas identificações, que podem ser vivenciadas, apreendidas e ressignificadas pelo artista para poetnografar na dança as singularidades e alteridades das mulheres do cerrado em seus ofícios de fiar e tecer manualmente, inventando "outras encruzilhadas".

\section{O LUGAR PARA ONDE SE OLHA - UNIVERSO DAS LINHAS DO BRASIL DE DENTRO, NAS RODAS E NA SOLITUDE}

O real não está na saída nem na chegada: ele se dispõe para a gente é no meio da travessia... (Guimarães Rosa, 1993)

Nesse Brasil de dentro, jardim de plantas tortas, ${ }^{1}$ existe um universo das linhas criado e mantido por mãos femininas. Mundos à parte. Mundo de várias. Mundo das linhas. Mulheres de linhas. Mãe, filha, avó, madrinha, irmã, comadre, neta, bisavó... suas paisagens, suas tramas, suas rodas, suas cantigas, suas linhas. Tecedura que nos atravessa como uma polifonia. Equipotência. Harmonia melódica das linhas. Linhas melódicas harmônicas. E, nas linhas, uma trama tão viva quanto a própria vitalidade dessas rodas femininas de fiação, tecelagem e tam- 
bém bordado, nas várias habilidades dessas mãos que criam mundos ao som de cantorias.

Nessas rodas, o desejo de criar. Desejo que nasce não da necessidade de adquirir algo que lhes falte, já que, a essas mulheres das linhas, por ter suas mãos tão cheias, quentes, fartas de tanta ternura, sabedoria, expansão, vida, nada falta, embora muitas dessas rodas fiquem em lugares desse sertão sem fim esquecidos do resto do país. No entanto, percebe-se um desejo que nasce como um impulso de criação, pois "viram na vida algo de grande demais", para tomar emprestadas as palavras de Deleuze e Gattari (1992), pondo nelas uma delicada marca de vida. E assim, mesmo daquelas que se encontram rodeadas de situações precárias, as casas são verdadeiros jardins, coloridas por suas criações manuais. E suas mãos, sempre férteis, a criar.

E, assim, elas criaram as rodas... Com a mesma delicadeza e habilidade com que agenciam seus fios, tecendo tramas de uma colcha fina de tecido, elas fazem uma torção sobre a própria condição do trabalho doméstico feminino, o "ser prendado", e criam juntas suas rodas de fiação, tecelagem, bordados... reinventando-se em um novo pedaço de terra, de encontro com outras mães, avós, meninas, transbordando a mulher do lar em direção a um corpo coletivo de criação, no qual a sua criação é a criação vinda e lançada para várias mulheres. Uma coletividade anônima na singularidade. Encontros, trocas, histórias, cantorias, paisagens, saberes, solidariedade, linhas. Um corpo de linhas. Enquanto isso, é criada uma grande quantidade de fios e peças, suprindo a necessidade da família e da comunidade.

Diante de toda essa potência expressiva, não é de estranhar que dona Maria I, a louca, tenha mandado destruir todos os teares, rodas, fios, com o alvará de 5 de janeiro de 1785. Ela viu nos resultados criativos das mãos de várias mulheres mineiras "algo de grande demais" para uma colônia. A promissora independência das importações de tecidos da Inglaterra, que o desenvolvimento da tecelagem e dos bordados promovia, criou uma situação crítica para Portugal, que dependia militarmente da proteção da Inglaterra.

Em resposta a essa autonomia que os ofícios das linhas ofereciam, com o argumento de que a produção têxtil e de bordados traria grave prejuízo à lavoura e à exploração mineral, o alvará (apud FONSECA et al., 1984, p. 4) proíbe "todas as fábricas, manufaturas ou teares de galões, de tecido ou de bordados de ouro e prata, veludo, brilhantes, cetins, tafetás, ou de qualquer outra qualidade de seda". Dona Maria I redige ainda outro alvará (apud CáURIO, 1985, p. 74) em 26 de janeiro do mesmo ano, ordenando que "fossem abolidas pela brandura ou violência as ditas fábricas e manufaturas no território de sua jurisdição", o que aca- 
bou por desencadear perseguições às manufaturas e aos proprietários dos teares, que agora só podiam tecer peças grosseiras para empacotar fazendas e vestir escravos. Isso porque os tecidos e bordados produzidos no Brasil não eram propriamente rudimentares e começavam a concorrer com a própria produção portuguesa e a inglesa.

O que dona Maria I e os governantes das capitanias não sabiam é que o mundo das linhas se reinventa por meios das mãos habilidosas de uma fiandeira, tecelã, bordadeira.... sendo assim impossível sua extinção. Vivendo em meio à clandestinidade, essas mulheres das linhas fizeram surgir fios e criações de lugares não imaginados, e hoje podemos ver nas rodas que se atualizam em localidades desse Brasil adentro, um fio que liga e religa essas várias mãos, paisagens à parte.

A ludicidade permeia essas rodas. Não só porque existem muitas crianças que as integram - ora bordando, cardando, enrolando novelo, ora bagunçando efetivamente a organização das linhas, transformando tudo numa grande brincadeira -, mas também porque as fiandeiras fazem de seu encontro um canal para que a vida se expresse na forma de brincadeiras. Algo como afirma Lygia Hortélio (2014, p. 275) em entrevista acerca do espaço da brincadeira, do lúdico:

É preciso descobrir novas formas de convívio, perspectivas de contato inteligente que resultem em verdadeiro ENCONTRO! Quem aprende o que, com quem, onde?! A ALEGRIA é fundamental, impres-cin-dí-vel! Reconhecer-se CRIANÇA, afirmar a VIDA, BRINCAR... Este seria o chão, o começo... O resto?! Isto vem!

Assim, sejam jovens, meninas ou bem velhas, elas desmancham o bordado de uma. Lançam verso de improviso para a lentidão da cardeira. Trocam o tecido da de lá. Inventam histórias para aquela que sempre acredita em tudo que se fala ou mesmo para aquela que gosta mais de uma fofoca. Tudo sempre em clima em que se percebe a vida se expressar ao ver a brincadeira instalar-se.

Existe também o trabalho na solitude, que é diferente de solidão, como mencionou uma dessas mulheres de linhas bem idosa, dona Fátima (25/11/2014): "quando estou com minhas linhas na solitude, estou ligada com todas as mulheres que tenho ou tive amizade, e com todos os lugares por onde passei. Com tudo que vivi. Tudo está aqui nas minhas linhas", como se dissesse que a solidão é estar sozinha justamente por não se deixar povoar, e solitude é estar só, mas completamente povoada.

Mesmo que a tecelagem doméstica não seja mais uma tradição isolada nesse sertão sem fim e exista um diagnóstico negativo sobre a manutenção e a reprodução dessa atividade artesanal, já que sofreu tantas mudanças referentes à 
eliminação de algumas etapas do processo tradicional e a crescente substituição da matéria-prima local pela industrializada, como aponta Fonseca et al. (1984) e Rodrigues (2010), o ofício manual de fiar e tecer tem-se mantido vivo em algumas localidades de Goiás e Minas Gerais.

Fiandeiras e tecelãs continuam criando e reinventando esse saber tradicional tanto no meio rural quanto nas cidades. Encontrá-las hoje, atualizando sua tradição, em associações e cooperativas, como a Central Veredas (MG) e o Centro de Convivência de Idosos em Hidrolândia (GO), é nos propor a vivenciar pelo ofício de fiar e tecer um "entre" no passado e presente, uma encruzilhada, um encontro com uma tecedura local, povoada de movimentos, gestos, cantorias, afetos, histórias e paisagens que podem suscitar poetnografias dançadas sobre o devir mulher do cerrado brasileiro

\section{O LUGAR PARA ONDE CAMINHAMOS - POETNOGRAFIA DANÇADAS}

Como se apreende o sentido de uma maçã? Comendo-a.

(Fernando Pessoa)

Entrar no universo da fiação e tecelagem manual realizadas por mulheres de Hidrolândia (GO) e Vale do Urucuia (MG) tem aumentado nosso fascínio pelas linhas. Isso porque é pelas linhas e nas linhas que todo o processo é construído. Linhas, vale lembrar, oriundas de um chumaço de algodão que, pela velocidade posta na roda e nas habilidades das mãos de uma fiandeira, se transforma em fio. Fio que se transforma em linhas, que viram rolos e rolos de linhas. Linhas que contêm nelas mesmas uma infinita possibilidade de se ligar, "re-ligar", criar e recriar, várias vezes pela ação do tramar, repassar, manipular o tear. Linhas que se cruzam, sugerindo equipotência e multiplicidade que vai sendo tecida aos poucos. E aos poucos, diante de nossos olhos, materializam-se em tecidos, roupas finas, colchas... peças inteiras de artesanato.

Nesse momento nossas mãos estão cheias, quentes, inquietas e ávidas para criar algo feito à mão com todo o corpo. Tornar artesanal a experiência. Mundos à parte, mundo de várias, mundo das linhas. Nessas rodas, por meio dos afetos vividos que fazem vibrar o corpo, uma dança e uma vontade de cantar/tocar. Uma relação que traz no corpo a equipotência das linhas, criando sentidos, mundos, visibilidade para aquilo captado sob a forma de sensação. Multiplicidade, linhas, vozes. Num encontro que nos transborda de tal maneira, que perguntamos se não são essas mulheres que estão buscando uma pesquisa que as faça dançar e cantar. 
O lugar para onde se olha sugere uma potência poética que se observa tanto no corpo - gestos e ações presentes no processo de fiação e tecelagem, cantorias entoadas, histórias contadas e vividas - como na relação desse corpo com a paisagem do cerrado - plantio e colheita do algodão, processo de tingimento dos fios com pigmentos de plantas, relação afetiva com essa paisagem. O lugar ao qual se quer chegar passa primeiramente pela experiência no campo, que aqui podemos identificar como um "campo vivido", já que a experiência etnográfica é amplamente dilatada pelos sentidos. E, depois, pelos laboratórios de criação, em que procedimentos próprios para uma abordagem de dança brasileira contemporânea elaboram, a partir de técnicas e princípios de nossas danças populares, processos de improvisação e o repertório pessoal do artista; tudo isso é então acionado em uma pesquisa de linguagem para elaboração de poetnografias dançadas.

Se considerarmos que o corpo, via seus órgãos sensoriais e suas funções, tece sentidos com o mundo que só ele está em condições de entender imediatamente e sem reenvio, como postulou Gil (2005), compreenderemos a construção de poetnografias dançadas como algo que joga com essa potencialidade de afeto que o corpo apresenta, buscando na experiência com um território da cultura popular (a encruzilhada) o fio condutor para a construção de uma dramaturgia do corpo (som e movimento) em dança brasileira contemporânea.

A experiência afetiva na encruzilhada proporciona ao artista a apreensão, pelos sentidos, do significado que a envolve. Assim, uma cantiga, um movimento, um gesto da manifestação, tudo tem seu fundamento nos afetos da experiência em campo. Sem essa experiência, esses elementos podem facilmente transformar-se em caricaturas. A tradição de fiar e tecer manualmente nas cidades de Hidrolândia (GO) e Vale do Urucuia (MG), o cerrado, as mulheres (meninas, mães e avós) dessa região, as histórias, a cantiga e a musicalidade dentro dessa tradição apresentam-se a nossos olhos com grande potencial de encruzilhada poetnografando através da dança a transformação do algodão em tecido artesanal, trama feita por linhas que atravessam o corpo e a tecedura cênica a partir dos afetos vividos na roda de fiação e tecelagem.

Participar dessas rodas e fazer o corpo vibrar geram paisagens e melodias que serão construídas aos poucos, como numa fina e delicada colcha de algodão tecida e bordada à mão ao som da cantoria de uma senhora, jovem, menina. Uma dança que, com sua multiplicidade, lance um modo de sentir e vivenciar essas rodas das linhas. E, na escrita, lançar movimento e musicalidade como a própria vitalidade dessas mulheres de linhas. 
Na discussão proposta por Silva e Lima (2014) a potencialidade de transformar esses afetos vividos junto à encruzilhada em poetnografia dançada se materializa por meio das "matrizes", unidades mínimas da poetnografia dançada, carregando nelas o sentido por onde a tecedura deverá ser percorrida e construída.

$\mathrm{Na}$ abordagem de Silva (2012), essas matrizes são, na verdade, "pontos de encontros" de uma suposta harmonia entre a forma do movimento e a sensação, isto é, quando a ação corporal atinge plasticidade que preenche os olhos e, ao mesmo tempo, resolve-se no corpo do atuante organicamente. Essas matrizes são reconhecidas dentro de um estado corporal mergulhado em um campo de intensidade (corpo instalado) que proporciona ao artista escapar dos chavões pessoais e redimensionar as ações, criando nexos de sentidos próprios (SILVA, 2012).

A concepção de harmonia entre sensação e forma do movimento está relacionada com o apreendido nos afetos da encruzilhada durante experiência em campo. No entanto, apesar de a matriz daí resultar, na criação ela excede os estados perceptivos e as passagens afetivas dessa experiência, pois são ressignificados pelo corpo, durante o processo de busca das poetnografias dançadas, que em conjunto constituem a dramaturgia de uma montagem cênica ou performance. Assim, no trabalho de criação, as matrizes podem ser consideradas um impulso de vida, uma linha, que em suas várias entradas e saídas movimenta as linhas que formarão a composição cênica em questão, trazendo o sentido que deverá percorrer a tecedura dramatúrgica e pelo qual ela deverá ser construída. Linhas que, ao poucos, no processo e pelo processo, vão tecendo as poetnografias dançadas, uma tecedura tão viva quanto a própria vitalidade da encruzilhada vivenciada em campo.

\section{CONSIDERAÇÕES FINAIS}

No processo de fiação e tecelagem, o algodão é plantado, colhido e transformado em fios e, posteriormente, em peças de artesanato pelas mão hábeis e olhares sensíveis da fiandeira e da tecelã que reconhece no algodão esse potencial de fiação e tecelagem. No olhar sensível e etnográfico para o contexto sociocultural das fiandeiras e tecelãs de Hidrolândia (GO) e do Vale do Urucuia (MG) reside uma possibilidade de investigação e criação de poetnografias dançadas, isto é, de intersecções de realidades culturais (a do trabalho e da dança, a do cotidiano e da vida, a da fiandeira e da bailarina) para "transformação" da tradição de fiar e tecer nas regiões de Minas Gerais e Goiás em linhas que compõem uma dramaturgia em dança brasileira contemporânea. Primeiramente, partimos do pres- 
suposto de que, para se transformar é preciso conhecer a forma, daí a importância de conhecer e vivenciar a encruzilhada (SILVA, 2010).

A encruzilhada do trabalho de fiar e tecer é vista aqui como lócus tangencial de saberes que podem ser utilizados como mola propulsora de uma dança contemporânea que se arrisque nos limites e fronteiras da linha abissal observada por Boaventura de Souza Santos (2007).

Ao considerarmos a ideia, que vem sendo discutida desde Silva (2010), que o movimento na dança é o próprio pensamento do corpo e, por outro lado, que não há epistemologias neutras, surge o questionamento de como pensar o movimento do corpo na dança, como um "pensamento pós-abissal", isto é, na perspectiva de uma ecologia dos saberes, situando nossa perspectiva epistemológica na experiência social do outro lado da linha, não apenas nos cânones da dança cênica marcadamente europeus e norte-americanos. Assim, perpassamos as encruzilhadas das danças e rituais afro-brasileiras para desdobrar a noção de encruzilhada nas performances do cotidiano como plataforma epistemológica do fazer artístico.

\section{NOTA}

1 Segundo o pesquisador Altair Salles Barbosa (2014), jardins de plantas tortas foi como os primeiros grupos indígenas que povoaram a região central do Brasil denominaram o bioma cerrado.

\section{REFERÊNCIAS BIBLIOGRÁFICAS}

BARBOSA, Altair Salles. O piar da juriti pepena: narrativa ecológica da ocupação do cerrado. Goiânia: PUC-GO, 2014.

CÁURIO, RITA. Arte têxtil no Brasil. Brasília: Inap/MEC/Funarte/Secretaria de Cultura, 1985.

CARVALHO, José Jorge. O lugar da cultura tradicional na sociedade moderna. 0 Percevejo: revista de teatro, crítica e estética. Rio de Janeiro, n. 8, p 19-40, 2000.

COLLA, Ana Cristina. Caminhante, não há caminho. Só rastro. Tese (Doutorado em artes), Unicamp, Campinas, 2010.

DELEUZE, Gilles; GUATTARI, Felix. O que é filosofia? Rio de Janeiro: Ed. 34, 1992.

FONSECA et al. Tecelagem manual no Triângulo Mineiro: uma abordagem tecnológica. Brasília: MEC/Sphan, 1984.

GIL, José. O movimento total: o corpo e a dança. São Paulo: Iluminuras, 2005.

HORTÉLIO, Lygia. Musicalidade tradicional da infância. Entrevista a Dulcimarta Lemos Lino. Reflexão \& Vozes, v. 22, n. 1, 2014. Disponível em <http://online. unisc.br/seer/index.php/reflex/issue/current/showToc> 
MARTINS, Leda Maria. Afrografias da memória: o reinado do rosário no Jatobá. São Paulo: Perspectiva, 1997.

RODRIGUES, Ana Izaura Pina. A tecelagem manual em Brasília: uma investigação atropológica sobre o universo têxtil. Tese Doutorado, Antropologia, UnB, Brasília, 2010.

RODRIGUES, Graziela. Bailarino-pesquisador-intérprete: processo de formação. Rio de Janeiro: Funarte, 1997.

ROSA, Guimarães. Grande sertão: veredas. 3 ed. Rio de Janeiro: José Olympio, 1993.

SANTOS, Boaventura de Sousa. Para além do pensamento abissal: das linhas globais a uma ecologia dos saberes. Novos Estudos Cebrap, São Paulo, n. 79, p. 71-94, 2007.

SANTOS, Inaicyra Falcão. Corpo e ancestralidade: uma proposta pluricultural de dança-arte-educação. Salvador: EDUFBA, 2002.

SCHECHENER, Richard. Performance studies: an introduction. London; New York: Routledge, 2002.

SILVA, Renata de Lima. O corpo limiar e as encruzilhadas: a capoeira Angola e os sambas de umbigada no processo de criação em dança brasileira contemporânea. Tese (Doutorado em artes), Unicamp, Campinas, 2010. . Corpo limiar e encruzilhada: processo de criação na dança. Goiânia: UFG, 2012.

SILVA, Renata de Lima; LIMA, Marlini Dorneles. Entre raízes, corpos e fé: poetnografias dançadas. Revista Moringa Artes do Espetáculo, João Pessoa, v. 5, n. 2, jul.-dez. 2014.

TURNER, Victor W. O processo ritual: estrutura e antiestrutura. Petrópolis: Vozes, 1974.

Maria Fernanda C. Miranda é mestranda em artes da cena pela Universidade Estadual de Campinas.

Renata de Lima Silva é doutora em artes pela Unicamp e professora adjunta da Universidade Federal de Goiás.

Recebido em: 19/04/2015

Aceito em: 10/05/2015 